\title{
What Is the Effect of Matrices on Cartilage Repair? A Systematic Review
}

\author{
James D. Wylie MD, Melissa K. Hartley BA, \\ Ashley L. Kapron PhD, Stephen K. Aoki MD, \\ Travis G. Maak MD
}

Published online: 21 January 2015

(C) The Association of Bone and Joint Surgeons ( 2015

\begin{abstract}
Background Articular cartilage has minimal endogenous ability to undergo repair. Multiple chondral restoration strategies have been attempted with varied results.

Questions/purposes The purpose of our review was to determine: (1) Does articular chondrocyte transplantation or matrix-assisted articular chondrocyte transplantation provide better patient-reported outcomes scores, MRI morphologic measurements, or histologic quality of repair tissue compared with microfracture in prospective comparative studies of articular cartilage repair; and (2) which
\end{abstract}

Each author certifies that he or she, or a member of his or her immediate family, has no funding or commercial associations (eg, consultancies, stock ownership, equity interest, patent/licensing arrangements, etc) that might pose a conflict of interest in connection with the submitted article.

All ICMJE Conflict of Interest Forms for authors and Clinical Orthopaedics and Related Research ${ }^{\mathbb{R}}$ editors and board members are on file with the publication and can be viewed on request.

Clinical Orthopaedics and Related Research ${ }^{\circledR}$ neither advocates nor endorses the use of any treatment, drug, or device. Readers are encouraged to always seek additional information, including FDAapproval status, of any drug or device prior to clinical use. Each author certifies that all investigations were conducted in conformity with ethical principles of research

Electronic supplementary material The online version of this article (doi:10.1007/s11999-015-4141-0) contains supplementary material, which is available to authorized users.

J. D. Wylie, A. L. Kapron, S. K. Aoki, T. G. Maak ( $\square)$ Department of Orthopaedic Surgery, University of Utah, 590 Wakara Way, Salt Lake City, UT 84108, USA e-mail: Travis.Maak@hsc.utah.edu; travis.maak@gmail.com

M. K. Hartley

School of Medicine, University of Utah, Salt Lake City, UT, USA available matrices for matrix-assisted articular chondrocyte transplantation show the best patient-reported outcomes scores, MRI morphologic measurements, or histologic quality of repair tissue?

Methods We conducted a systematic review of PubMed, CINAHL, and MEDLINE from March 2004 to February 2014 using keywords determined to be important for articular cartilage repair, including "cartilage", "chondral", "cell source", "chondrocyte", "matrix", "augment", "articular", “joint”, "repair”, "treatment”, "regeneration", and "restoration" to find articles related to cell-based articular cartilage repair of the knee. The articles were reviewed by two authors (JDW, MKH), our study exclusion criteria were applied, and articles were determined to be relevant (or not) to the research questions. The Methodological Index for Nonrandomized Studies (MINORS) scale was used to judge the quality of nonrandomized manuscripts used in this review and the Jadad score was used to judge the quality of randomized trials. Seventeen articles were reviewed for the first research question and 83 articles were reviewed in the second research question from 301 articles identified in the original systematic search. The average MINORS score was $9.9(62 \%)$ for noncomparative studies and $16.1(67 \%)$ for comparative studies. The average Jadad score was 2.3 for the randomized studies.

Results Articular chondrocyte transplantation shows better patient-reported outcomes at 5 years in patients without chronic symptoms preoperatively compared with microfracture $(p=0.026)$. Matrix-assisted articular chondrocyte transplantation consistently showed improved patientreported functional outcomes compared with microfracture ( $p$ values ranging from $<0.001$ to 0.029 ). Hyalograft $C^{\circledR}$ (Anika Therapeutics Inc, Bedford, MA, USA) and Chondro-gide ${ }^{\circledR}$ (Genzyme Biosurgery, Kastrup, Denmark) are 
the matrices with the most published evidence in the literature, but no studies comparing different matrices met our inclusion criteria, because the literature consists only of uncontrolled case series.

Conclusions Matrix-assisted articular chondrocyte transplantation leads to better patient-reported outcomes in cartilage repair compared with microfracture; however, future prospective research is needed comparing different matrices to determine which products optimize cartilage repair.

Level of Evidence Level IV, therapeutic study.

\section{Introduction}

Articular cartilage is aneural and avascular and nourished only by synovial fluid. As a result of its lack of blood supply, it has minimal endogenous ability to repair articular surface defects [28]. Focal articular cartilage defects are common at the time of arthroscopy with $19 \%$ of arthroscopies having focal chondral or osteochondral defects [15]. Injured articular cartilage can lead to early joint degeneration if symptomatic and left untreated [31]; thus, multiple treatment strategies have been proposed for articular cartilage repair [30].

The most often used treatment in the United States is palliative chondroplasty followed by marrow stimulation techniques such as microfracture with restorative techniques, including autologous chondrocyte transplantation with osteochondral transfer being much less common [26]. Microfracture relies on perforation of the subchondral bone of the articular cartilage defect, leading to the egress of marrow components, including stem cells and growth factors to stimulate repair [12, 39]. Alternatively, either autogenous or allogeneic articular chondrocytes can be implanted into the defect in either a one-stage or a two-stage procedure. The implant procedure is referred to as autologous chondrocyte transplantation and, in the setting of juvenile allogeneic cartilage, is referred to as particulated juvenile articular cartilage. The currently available particulated juvenile articular cartilage in the United States is DeNovo-Natural Tissue (Zimmer, Warsaw, IN, USA) [9].

Implant procedures can also be supplemented with biologic matrices to stimulate cartilage matrix organization and synthesis. In the setting of microfracture, this is referred to as autologous matrix- (or collagen-)induced chondrogenesis $[11,37]$ and, in the setting of chondrocyte implantation, is known as matrix-assisted chondrocyte transplantation or second-/third-generation autologous chondrocyte transplantation, which is not currently available in the United States [20]. These biologic matrices are composed of cartilage extracellular matrix molecules or biopolymers that function as a scaffold for marrow components or transplanted chondrocytes to form more hyaline-like repair tissue in articular cartilage defects [35]. The matrices trap the repair cells in the chondral defect and provide cell-matrix interactions that are designed to stimulate differentiation into articular chondrocytes and production of hyaline-like extracellular matrix [35].

Controversies abound regarding the optimal cell-based chondral repair technique, because there are many emerging techniques, and there will be many choices for surgeons and patients to make. Currently, there are no approved matrix-based techniques in the United States, but outcomes have been reported elsewhere. Clear superiority has not been established of one technique over any other, and published studies have varied in terms of their quality and in terms of which techniques have been compared with one another; most reports remain uncontrolled case series or comparisons to microfracture. It seems to us that the main goals of treatment might be evaluated in light of clinical (pain- and function-related), radiographic (MRI morphologic evaluation), and histologic (cartilage healing and regeneration) endpoints, but studies have varied widely in terms of how these important endpoints have been assessed.

Given the controversies, we conducted a systematic review designed to address two fundamental questions: (1) Does articular chondrocyte transplantation or matrixassisted articular chondrocyte transplantation provide better patient-reported outcomes scores, MRI morphologic measurements, or histologic quality of repair tissue compared with microfracture in prospective comparative studies of articular cartilage repair; and (2) which available matrices for matrix-assisted articular chondrocyte transplantation show the best patient-reported outcomes scores, MRI morphologic measurements, or histologic quality of repair tissue?

\section{Search Strategy and Criteria}

Two authors (JDW, MKH) independently conducted a comprehensive review of citation databases PubMed, CINAHL, and MEDLINE to confirm that each search was comprehensive and reproducible. Search terms included: "cartilage", "chondral", "cell source", "chondrocyte", "matrix", "augment", "articular", “joint", "repair", "treatment", "regeneration", and "restoration". All searches were performed with the last letter replaced by an asterisk to capture further articles. The final search term entered in the search fields included a combination of two searches: (1) "articular" OR "joint" AND "repair" OR "treatment" OR "regeneration" OR "restoration"; and (2) "cartilage" OR "chondral" AND "cell source" OR "chondrocyte" OR "matrix" OR "augment". The search 
date range was March 1, 2004, to February 28, 2014. For all three search engines, filters for English language and human subjects were applied. PubMed and MEDLINE searches included an additional filter of clinical trials, which was not available in CINAHL.

The PubMed search yielded 137 articles; the CINAHL search yielded 190 articles; and the MEDLINE search yielded 48 articles. The searches were then combined into one database to remove duplicate papers and we were left with 301 articles to consider. Abstracts were then reviewed for relevance to the proposed research questions. Only articles relating to cell-based articular cartilage repair of the knee were considered. Articles pertaining to osteochondral autograft or allograft transplantation were excluded. In addition, all unpublished studies, proceedings/ abstracts, and non-English language studies were excluded from our analysis. The reference lists of selected articles were then searched to identify relevant articles that may have been missed by the initial search process. Available matrices for matrix-assisted chondrocyte transplantation identified in our systematic search were then searched by name in PubMed to ensure a comprehensive inclusion of available articles for each product.

All Levels of Evidence (I-IV) were considered. Case series and retrospective studies (Levels of Evidence III and IV) were excluded for the comparison of microfracture, autologous chondrocyte transplantation, and matrix-assisted chondrocyte transplantation as a result of the availability of more rigorous randomized controlled trials and prospective comparative studies (Level of Evidence I or II). Alternatively, because of limited availability of prospective comparative studies designed to evaluate different matrices for matrix-assisted chondrocyte transplantation, all Levels of Evidence (I-IV) were considered (Fig. 1). As a result of our decision to include retrospective reports, we could not pool data or formally analyze publication bias or heterogeneity.

Seventeen studies were identified that were relevant to our first research question and met the inclusion and exclusion criteria. These studies are described individually in Appendices 1 and 2 (Supplemental materials are available with the online version of CORR ${ }^{\circledR}$ ). Eleven different matrix-based techniques were identified in our search (Table 1). Hyalograft ${ }^{\circledR} \mathrm{C}$ (Anika Therapeutics Inc, Bedford, MA, USA) and matrix-assisted chondrocyte implantation (MACI ${ }^{\circledR}$ Chondro-gide ${ }^{\circledR}$ membrane [Genzyme Biosurgery, Kastrup, Denmark]) are the most commonly reported procedures with $\mathrm{MACI}^{\circledR}$ having been completed in 6000 patients worldwide [5]. The search identified 83 articles on 11 matrices: $\mathrm{MACI}^{\mathbb{R}} /$ Chondrogide ${ }^{\circledR}, 27$ articles; Hyalograft ${ }^{\circledR}$ C, 21 articles; Bioseed ${ }^{\circledR} \mathrm{C}$ (BioTissues Technology, Freiburg, Germany), six articles; Cartilage Regeneration System $\left(\mathrm{CaReS}^{\circledR}\right.$ ) (Arthro Kinetics

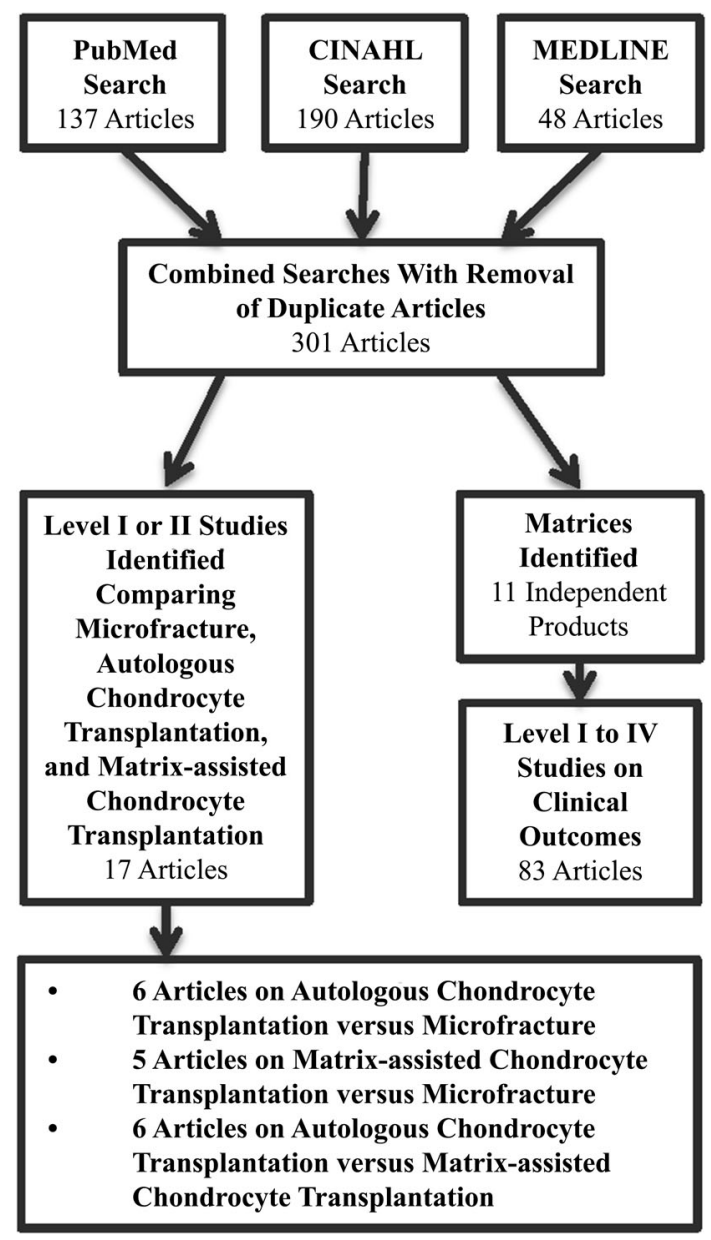

Fig. 1 Flow diagram shows systematic search for study articles.

Biotechnology, Krems/Danube, Austria) and atelocollagen (RMS Innovations UK, Hertfordshire, UK), five articles each; Novocart ${ }^{\mathbb{R}}$ 3D (Aesculap Implant Systems LLC, Center Valley, PA, USA), five articles; osteochondral biomimetic scaffold, three articles; NeoCart ${ }^{\mathrm{TM}}$ (Histogenics, Waltham, MA, USA), Chondron ${ }^{\mathrm{TM}}$ (Sewon Cellontech, Seoul, Korea), and DeNovo-NT, two articles each; and Cartipatch ${ }^{\mathbb{R}}$ (Tissue Bank of France, Lyon, France), and Condrograft ${ }^{\circledR}$ (BR Medical, Monterrey, Mexico), one article each. Of note, Hyalograft ${ }^{\circledR} \mathrm{C}$ has been recently removed from the European market by the European Medical Association as a result of concerns with manufacturing processes and the design of clinical studies that were submitted for preliminary approval prompting the company to remove their application for approval.

Quality of the literature was quantified by the Methodological Index for Nonrandomized Studies (MINORS) scale for nonrandomized studies and the Jadad scale for randomized studies. The average Jadad score for the 12 randomized studies was 2.3 out of 5 . The average MINORS score for comparative studies was 16.1 out of $24(67.3 \%)$ 
Table 1. Matrix-assisted chondrocyte transplantation implants

\begin{tabular}{|c|c|}
\hline Implants & Description \\
\hline Hyalograft $\mathrm{C}$ & Scaffold composed of Hylaff11, a benzyl esther of hyaluronic acid \\
\hline CaReS/CaReS-1S & $\begin{array}{l}\text { 3-D Type I collagen matrix purified from rat-tail collagen; CaReS-1S used in single-stage surgery without } \\
\text { cocultured cells }\end{array}$ \\
\hline Chondro-gide/MACI & $\begin{array}{l}\text { Bilayer membrane made of porcine Type I/III collagen; Chonro-gide used as collagen membrane for traditional } \\
\text { ACI, MACI when cells precultured with membrane }\end{array}$ \\
\hline NeoCart & Type I collagen scaffold cultured with cells in a bioreactor to create implant \\
\hline Novocart 3D & 3-D Type I collagen scaffold with chondroitin sulfate \\
\hline Atelocollagen & $\begin{array}{l}\text { 3\% Type I collagen gel covered in either a periosteal, synovial tissue flap or collagen membrane, or mixed with } \\
\text { fibrinogen/thrombin }\end{array}$ \\
\hline Cartipatch & Vegetal hydrogel composed of agarose and alginate \\
\hline Bioseed C & Scaffold composed of fibrin, polyglycolic/polylactic acid with polydioxanone \\
\hline Chondron & Fibrin gel compound mixed in 1:1 ratio with chondrocyte suspension \\
\hline Condrograft & Tridimensional matrix of semisolid collagen \\
\hline $\begin{array}{l}\text { Osteochondral biomimetic } \\
\text { scaffold }\end{array}$ & $\begin{array}{l}\text { Three-layered biomimetic scaffold with Type I collagen in the cartilage layer, } 60 \% \text { Type I collagen and } 40 \% \\
\text { hydroxyapatite in the tidemark layer, and mineralized blend of } 30 \% \text { Type I collagen and } 70 \% \text { hydroxyapatite in } \\
\text { the subchondral bone layer }\end{array}$ \\
\hline DeNovo-NT & Particulated juvenile allograft articular cartilage placed into the defect with fibrin glue \\
\hline
\end{tabular}

3-D = three-dimensional; CaReS = Cartilage Regeneration System, CaReS-1S Cartilage Regeneration Systems One Step' MACI = matrixassisted chondrocyte implantation; ACI = autologous chondrocyte implantation; NT = natural tissue.

and the average score for non-comparative studies was 9.9 out of $16(61.6 \%)$.

A systematic review of the selected articles was performed to extract: number of patients, Level of Evidence, length of followup, size of defect treated, matrix used (if applicable), patient-reported outcomes measured, MRI morphologic evaluation scale used, histologic grading scale measured, and other pertinent findings reported.

\section{Results}

Studies Comparing Microfracture, Chondrocyte Transplantation, and Matrix-assisted Chondrocyte Transplantation

Randomized and comparative studies of patient-reported outcomes measures, radiologic evaluation, and histologic evaluation of autologous chondrocyte transplantation compared with microfracture showed varying results with matrix-assisted collagen transplantation techniques demonstrating better patient-reported outcomes than autologous chondrocyte transplantation when compared with microfracture (Appendix 1).

In six studies comparing autologous chondrocyte transplantation with microfracture that described three distinct groups of patients, early studies showed no difference in patient-reported outcome measures between the two methods $[17,18,42]$; however, two studies at 3 and 5 years postoperatively in the same study group found improved patient-reported outcomes with autologous chondrocyte transplantation compared with microfracture when controlling for patient duration of symptoms before surgery. Patients with less than 3 years of symptoms before undergoing autologous chondrocyte transplantation had 10point higher overall Knee Injury and Osteoarthritis Outcome Scores (KOOS) compared with microfracture at 5 years postoperatively $(p=0.026$ for overall KOOS) $[33$, 43]. However, patients who had lesions with chronicity of symptoms greater than 3 years had poorer outcomes with autologous chondrocyte transplantation [43]. Microfracture outcomes worsened with larger lesions, whereas autologous chondrocyte transplantation outcomes did not [18]. At 1 year postoperatively, autologous chondrocyte transplantation showed better histomorphometry $(\mathrm{p}=0.003)$ and overall histologic evaluation $(\mathrm{p}=0.012)$ scores on biopsy specimens compared with microfracture [34].

All five comparative studies of matrix-assisted chondrocyte transplantation and microfracture showed significant improvements at 2- to 7.5-year followup in International Knee Documentation Committee (IKDC) scores: 12-point increase at 5 years $(p<0.001)[21]$ and 17 point increase at mean 7.5 years $(p=0.005)$ [19]; Lysholm scores: 26-point increase at 2 years $(\mathrm{p}=0.005)$ [4]; and all KOOS subscores: approximately 10 points higher for all scales at 2 years ( $\mathrm{p}$ values ranging from $<0.001$ to 0.029 ) [32]; Appendix 1). Prospective comparative studies between autologous chondrocytes transplantation and matrix-assisted chondrocyte transplantation showed more hyaline-like tissue in the matrix-assisted group $(\mathrm{p}=0.01)$ [25] 
Table 2. Functional outcomes of different matrix-assisted chondrocyte transplantation implants

\begin{tabular}{llll}
\hline Implants & $\begin{array}{l}\text { Followup } \\
\text { (years) }\end{array}$ & $\begin{array}{l}\text { Number of studies } \\
\text { (Level of Evidence) } \\
\text { (number of patients) }\end{array}$ & $\begin{array}{l}\text { Mean lesion } \\
\text { size }\left(\mathrm{cm}^{2}\right)\end{array}$
\end{tabular}

Hyalograft C

Hyalogrt $\mathrm{C}$

\author{
2, 3, 5, 6, and 7; 19 (1-I, 3-II, 15-IV)-908 2.1-4.5 \\ some patients, \\ up to 10
}

$\begin{array}{llll}\text { CaReS/CaReS-1S } & 2 \text { and } 4 & 2 \text { (2-IV)-131 } & 0.8-5.4 \\ \text { Chondro-gide/MACI } & 2 \text { and } 5 & 22 \text { (4-I, 1-II, 17-IV)-799 } & 2.7-8.3\end{array}$

Chondro-gide/MACI

$$
22 \text { (4-I, 1-II, 17-IV)-799 }
$$

\section{NeoCart}

Novocart 3D
2

2
2 (2-IV)-38

4 (4-IV)-127

3 (3-IV)-114

1 (1-IV)-17

5 (1-III, 4-IV)-162

$2(2-I V)-128$

\begin{tabular}{|c|c|c|c|}
\hline Atelocollagen & 2 and $5 / 6$ & 3 (3-IV)-114 & $3.6-3.75$ \\
\hline Cartipatch & 2 & 1 (1-IV)-17 & 3.0 \\
\hline Bioseed C & 2 and 4 & 5 (1-III, 4-IV)-162 & $3.5-4.8$ \\
\hline Chondron & 2 & $2(2-I V)-128$ & $5.2-5.8$ \\
\hline Condrograft & 1 & $1(1-I V)-15$ & $\begin{array}{l}\text { No mean } \\
\text { reported; } \\
\text { range } \\
1.5-8.0\end{array}$ \\
\hline $\begin{array}{l}\text { Osteochondral } \\
\text { biomimetic scaffold }\end{array}$ & 2 and 5 & 3 (3-IV)-84 & $2.9-3.5$ \\
\hline DeNovo-NT & 2 & 2 (2-IV)-43 & 2.7 and 2.4 \\
\hline
\end{tabular}

30- to 40-point increase in IKDC scores; 25- to 35-point increases in Lysholm scores; 3- to 4-point increase in the Tegner activity scale; outcomes improved for up to 2 years, then stable through midterm; less improvement in patients with underlying osteoarthritis, patellar lesions, and lower preoperative scores; improved outcomes in younger patients with single defects; underlying osteoarthritis led to decreased scores from 2 years to midterm

25- to 30-point increase in IKDC scores; decrease in VAS pain score by 2 to 3.5 points; improvement in SF-36 PCS by 8 points; similar scores at 2 and 4 years

25- to 40-point increases in IKDC scores; 25- to 30-point increases in KOOS subscales; improvement in quality of life and sports subscales from 2 to 5 years; otherwise stable scores from 2 to 5 years; 25 - to 40 -point increases in Lysholm scores; 3- to 4-point decreases in VAS pain scores; outcomes improved at 2 years with accelerated rehabilitation protocols; generally worse outcomes with multiple lesions, longer symptoms, and isolated patella lesions

25- to 35-point increases in IKDC scores; 2-point improvement in VAS pain scores; 15-point improvement in KOOS pain score

20- to 35-point increases in IKDC scores; less improvement in series with larger lesions; decreases in VAS pain by 2 to 3 points; increase in Tegner activity scores by 2 points; improvement in KOOS subscores by 20 to 30 points with normal scores in pain/ADL; lower scores in sports and quality of life; better scores at 2 years in patient who returned to sports at $>12$ months postoperatively

30-point increases in Lysholm score and original knee score; Lysholm scores in 90s at midterm followup; improvement to 2 years, then stable at midterm

40-point improvement in IKDC scores

30- to 35-point improvement in Lysholm scores; 20- to 25point improvement in IKDC scores; similar improvements at 2 and 4 years

Approximately 40-point improvement in Lysholm score, Knee Society scores (A and B), and Cincinnati knee score; 5-point improvement in Tegner activity score; improvement in KOOS subscores by 10 to 30 points with greatest improvement in sports scale, but lowest overall scores in sports and quality of life

KOOS scores of 84 at 1-year follow-up; WOMAC improved from 56 to 17 (no published 2-year followup)

35- to 40-point improvements in IKDC scores; 2- to 2.5point improvement in Tegner; improvement up to 2 years, then stable at 5 years

25-point improvements in IKDC; 3-point decrease in VAS pain; 20-point increases in all KOOS subscales, with lower overall scores in sports and quality of life; similar final followup scores between condyle and patella lesions

$\overline{\mathrm{CaReS}}=$ Cartilage Regeneration System, CaReS-1S Cartilage Regeneration Systems One Step; IKDC = International Knee Documentation Committee; VAS = visual analog scale; PCS = Physical Component Summary; KOOS = Knee Injury and Osteoarthritis Outcomes Score; $\mathrm{ADL}=$ activities of daily living; $\mathrm{NT}=$ natural tissue. 
Table 3. MRI outcomes of different matrix-assisted chondrocyte transplantation implants

\begin{tabular}{|c|c|c|c|}
\hline Implants & $\begin{array}{l}\text { Followup } \\
\text { (years) }\end{array}$ & $\begin{array}{l}\text { Number of studies } \\
\text { (Level of Evidence) } \\
\text { (number of patients) }\end{array}$ & MRI evaluation \\
\hline Hyalograft $\mathrm{C}$ & $2-7$ & 8 (3-II, 5-IV)-241 & $\begin{array}{l}\text { MOCART scores in the low 70s, dGEMRIC values approximately } 80 \% \text { of normal } \\
\text { hyaline cartilage; most studies subjective description of MRI findings without } \\
\text { quantification; majority of patients with good to complete filling of defect }\end{array}$ \\
\hline $\mathrm{CaReS} / \mathrm{CaReS}-1 \mathrm{~S}$ & 2 and 4 & 2 (1-II, 1-IV)-25 & $\begin{array}{l}\text { MOCART scores in the high } 70 \mathrm{~s} \text {, improving to the } 80 \mathrm{~s} \text { at } 4 \text { years in small patient } \\
\text { population with small defects }\left(80 \mathrm{~s} \text { in defects }<1 \mathrm{~cm}^{2} \text { ) }\right.\end{array}$ \\
\hline $\begin{array}{l}\text { Chondro-gide/ } \\
\text { MACI }\end{array}$ & 2 and 5 & 14 (1-II, 13-IV)-534 & $\begin{array}{l}\text { MOCART scores in the high } 60 \mathrm{~s} \text { to } 70 \mathrm{~s} ; \mathrm{T} 2 \text { scores similar to control hyaline } \\
\text { cartilage; majority had good-to-complete defect filling }\end{array}$ \\
\hline NeoCart & 2 & $1(1-\mathrm{IV})-8$ & $\begin{array}{l}\text { Majority had good-to-complete defect fill but repair areas had continued } \\
\text { prolongation at } 2 \text { years, indicating repair tissue structurally different from control } \\
\text { cartilage }\end{array}$ \\
\hline Novocart 3D & 2 & $43(3-I V)-83$ & $\begin{array}{l}\text { MOCART scores high } 60 \text { s to mid-70s at 2-year followup; improvement from 1- to } \\
\text { 2-year followup }\end{array}$ \\
\hline Atelocollagen & 2 and $>5$ & $2(2-I V)-84$ & $\begin{array}{l}\text { MOCART scores in the low 70s at } 2 \text { years and greater than at 5-year followup; } \\
\text { improvement between 1- and 2-year followup, without significant improvement } \\
\text { after } 2 \text { years }\end{array}$ \\
\hline Cartipatch & 2 & $1(1-\mathrm{IV})-15$ & Majority with defect fill and "signal similar to surrounding cartilage" \\
\hline Bioseed C & 2 & 3 (1-II, 2-IV)-70 & $\begin{array}{l}\text { Majority had good-to-complete defect filling with normal to hyperintense signal } \\
\text { intensity }\end{array}$ \\
\hline Chondron & 2 & $1(1-\mathrm{IV})-30$ & Mean Henderson MRI scores improved from 14.4 to 7.0 at 2-year followup \\
\hline Condrograft & NA & NA & No reported MRI studies \\
\hline $\begin{array}{l}\text { Osteochondral } \\
\text { biomimetic } \\
\text { scaffold }\end{array}$ & 2 and 5 & $3(3-\mathrm{IV})-68$ & $\begin{array}{l}\text { MOCART scores improved from high } 60 \text { s to } 70 \text { s at } 1 \text { and } 2 \text { years to mid-70s at } 5 \text { - } \\
\text { year followup; showing improved integration into subchondral bone over time }\end{array}$ \\
\hline Denovo-NT & 2 & $2(2-I V)-43$ & Majority had complete defect filling; T2 signal similar to control cartilage \\
\hline
\end{tabular}

CaReS = Cartilage Regeneration System, CaReS-1S Cartilage Regeneration Systems One Step; MOCART = MR observation of cartilage repair tissue; dGEMRIC $=$ delayed gadolinium-enhanced MRI of cartilage; MACI $=$ matrix-assisted chondrocyte implantation; NA $=$ not applicable; NT $=$ natural tissue.

(Appendix 2). However, findings from the studies also showed no difference in patient-reported outcome scores between matrix-assisted chondrocyte transplantation and autologous chondrocytes transplantation [3, 10, 14, 23, 44].

Studies on Matrices for Matrix-assisted Cartilage Repair

Overall, each product has similar improvements in patientreported outcome scores as a result of surgery in the literature. These have been aggregated from Level I to Level IV studies (Table 2). However, given the predominance of case series data and paucity of reports directly comparing two techniques, we could not control for defect size or other confounding variables. For example, some matrices were mostly used in patients with relatively smaller defects (Hyalograft ${ }^{\circledR} \mathrm{C}, \mathrm{NeoCart}{ }^{\mathrm{TM}}$ ), whereas others were mostly used in patients with large defects $\left(\right.$ MACI ${ }^{\circledR}$, Novocart $3 \mathrm{D}^{\mathrm{R}}$, Chondron $\left.{ }^{\mathrm{TM}}\right)$. Nonetheless, most matrices had similar MR observation of cartilage repair tissue (MOCART) scores and defect fill at 1- or 2-year followup, signifying a similar tissue healing response (Table 3). There was a scarcity of histologic data, but most outcomes showed a majority of hyaline-like and mixed hyaline/fibrocartilage repair tissue with $50 \%$ of cases that used this measure reported as hyaline-like (Table 4). Direct comparison of the data was again difficult because the studies included patients who had biopsies at different time points after surgery. The tissue appeared to mature for at least 18 months after surgery with more hyaline-like tissue from biopsies the further out from surgery [24].

Autologous matrix- (or collagen-) induced chondrogenesis have shown good short-term (2-year) clinical outcomes. Autologous matrix-induced chondrogenesis, with the use of Chondro-gide ${ }^{\circledR}$, demonstrated a 4-point decrease in visual analog scale (VAS) pain scores and a 35-point improvement in Lysholm scores at 2 years [11]. Autologous collageninduced chondrogenesis, with the use of atelocollagen, demonstrated a 30-point increase in Lysholm scores at 2 years [37]. Additionally, MRI followup data demonstrated reparative tissue with similar $\mathrm{T} 2$ characteristics to hyaline cartilage at 1-year followup after autologous collageninduced chondrogenesis [40]. However, the only 
Table 4. Histologic analyses of patient samples from different matrix-assisted chondrocyte transplantation implants

\begin{tabular}{|c|c|c|c|}
\hline Product & $\begin{array}{l}\text { Number of studies (Level } \\
\text { of Evidence) (number of } \\
\text { patients with biopsy) }\end{array}$ & $\begin{array}{l}\text { Time of biopsy } \\
\text { postoperatively }\end{array}$ & Histologic findings \\
\hline Hyaolgraft $\mathrm{C}$ & 3 (1- II, 2- IV)-34 & Mean: $12-15$ months & $\begin{array}{l}23 \text { with hyaline-like tissue; } 6 \text { with mixed hyaline/ } \\
\text { fibrocartilage; and } 5 \text { with predominantly fibrocartilage }\end{array}$ \\
\hline CaReS/CaReS-1S & 1 (IV)-1 & 16 months & $\begin{array}{l}\text { Predominantly hyaline cartilage at time of revision } \\
\text { meniscectomy (CaReS-1S) }\end{array}$ \\
\hline Chondro-gide/MACI & $5(1-\mathrm{I}, 4$ - IV)-80 & Mean: $12-18$ months & $\begin{array}{l}30 \text { with hyaline-like tissue; } 40 \text { with mixed hyaline/ } \\
\text { fibrocartilage or fibrocartilage }\end{array}$ \\
\hline NeoCart & 0 & NA & NA \\
\hline Novocart 3D & 0 & NA & NA \\
\hline Atelocollagen & 1 (IV)-40 & 12 months & $\begin{array}{l}\text { ICRS visual assessment score II: mean 70; average mixed } \\
\text { hyaline/fibrocartilage }\end{array}$ \\
\hline Cartipatch & 1 (IV)-13 & 24 months & $\begin{array}{l}8 \text { of } 13 \text { patients with predominantly hyaline cartilage; mean } \\
\text { O'Driscoll histology score: } 16 / 21 \text {; mean ICRS histology } \\
\text { score: } 14 / 18\end{array}$ \\
\hline Bioseed C & $1(\mathrm{IV})-4$ & 9 to 12 months & $\begin{array}{l}3 \text { of } 4 \text { patients with predominantly hyaline cartilage; } 1 \text { with } \\
\text { mixed hyaline/fibrocartilage }\end{array}$ \\
\hline Chondron & 0 & NA & NA \\
\hline Condrograft & 0 & NA & NA \\
\hline $\begin{array}{l}\text { Osteochondral } \\
\text { biomimetic scaffold }\end{array}$ & 1 (IV)-1 & 2 years & $\begin{array}{l}1 \text { patient with hyaline-like tissue taken at time of hardware } \\
\text { removal }\end{array}$ \\
\hline DeNovo-NT & 1 (IV)-8 & 2 years & $\begin{array}{l}\text { Immunopositivity for Type II collagen higher than type I in } 6 \\
\text { of } 8 \text { samples; mostly hyaline-like or mixed hyaline/ } \\
\text { fibrocartilage }\end{array}$ \\
\hline
\end{tabular}

CaReS = Cartilage Regeneration System, CaReS-1S Cartilage Regeneration Systems- One Step; NA = not applicable; ICRS = International Cartilage Repair Society; NT = natural tissue.

comparative study between autologous matrix-induced chondrogenesis and microfracture was hampered by the inability to recruit enough patients into the trial; as such, meaningful comparisons could not be made [2]. Cartilage Regeneration System-One Step (Arthro-Kinetics Biotechnology, Krems/Danube, Austria) is a similar single-step cellfree procedure for treating smaller defects that uses the same membrane as Cartilage Regeneration System and its use has shown a 30-point increase in patient IKDC scores and a 2.5point decrease in VAS pain scores at 4-year followup [36].

\section{Discussion}

Articular cartilage defects are common in patients undergoing arthroscopy [15]; however, the most frequently used US treatments are designed to address symptoms without restoring hyaline cartilage [26]. Cartilage restoration techniques have evolved in the last 20 years, from microfracture to autologous chondrocyte transplantation, and matrix-assisted chondrocyte transplantation is available outside the United States. Given the rapid expansion in treatment options, we sought to provide an evidence-based answer to two fundamental comparative questions in cartilage restoration: (1) Does articular chondrocyte transplantation or matrix-assisted articular chondrocyte transplantation provide better patient-reported outcomes scores, MRI morphologic measurements, or histologic quality of repair tissue compared with microfracture in prospective comparative studies of articular cartilage repair; and (2) which available matrices for matrix-assisted articular chondrocyte transplantation show the best patientreported outcomes scores, MRI morphologic measurements, or histologic quality of repair tissue ?

The literature we reviewed to answer the questions had several important limitations. There were few high-quality comparative studies on cartilage repair techniques. This was illustrated by our evaluation of the studies reviewed in the Methods section. The studies most often compared either autologous chondrocyte transplantation or matrixassisted chondrocyte transplantation with microfracture, which is currently considered the gold standard technique by regulatory agencies. There were fewer well-controlled studies comparing matrix-assisted chondrocyte transplantation with autologous chondrocyte transplantation. Even in the setting of well-controlled studies, subanalyses showed that factors significantly affecting outcomes were only discovered in posttrial analyses such as the impact of duration of patient symptoms before treatment. This fact clouded some of the early studies comparing autologous 
chondrocyte transplantation with microfracture. Previous studies may have demonstrated more striking results if patient duration of symptoms had been required in the inclusion criteria [33]. Regarding our second question, there was almost no literature comparing different matrices. This body of literature relies almost completely on uncontrolled case series or comparative studies of matrixassisted chondrocyte transplantation and microfracture or autologous chondrocyte transplantation. This precluded the ability to draw strong conclusions in light of confounding variables such as defect size and alignment of the joint, variables that we know are critical to the outcome and survivorship of cartilage repair procedures [13]. Overall, the heterogeneity of the studies on cell-based cartilage repair with or without matrix-assisted technologies precluded us from performing a pooled data analysis to help us answer our research questions. This leads to difficulty in making any definitive conclusions based on the data currently available.

Another important limitation is the publication bias of studies with positive results. Studies with positive results are much more likely to be published and to be published in journals with a higher impact factor [8]. The report of new technologies and procedures is more likely to be published if their outcomes are positive, this can be driven by the company developing the product, the investigators performing the trial as well as journal reviewers and editors that control whether a study is published. This leads to likely an overestimation of the treatment effect of new technologies based on the preliminary studies and belies the need for well-controlled clinical trials. Despite these limitations, the current study summarizes the promise of matrix-assisted chondrocyte transplantation as a potential improvement in our treatment of focal cartilage defects while pointing out what is needed to further our understanding of this technology.

Cartilage repair is an evolving field. The only conclusion that could be drawn from high-quality studies in the available literature was that matrix-assisted chondrocyte transplantation has led to better patient-reported outcomes than microfracture without definitive clinical evidence to show better morphologic repair tissue on MRI or histologic analysis. Unfortunately, the clinical outcomes used in all of these studies are short-term surrogate markers for the most important outcome of joint preservation or conversion to knee arthroplasty. To definitively determine the best technique for cartilage repair, we will need long-term highquality studies that determine which of these techniques helps patients delay the need for knee arthroplasty. Ideally, this would come from large randomized controlled studies of patients with the three techniques discussed. In lieu of this evidence, large prospectively collected cohorts with homogenous data collection methods as suggested by the
International Cartilage Repair Society [16, 29] could help give us a more definitive answer to this question. This would include consistent use of uniform patient-reported measures of pain and function, MRI morphologic measures, and histologic analysis methods. In addition, these cell-based techniques will need to be compared with other techniques not detailed in this review including osteochondral transplantation to understand the best procedures for patients. Microfracture is an accepted treatment for small lesions, but it is not the current treatment of choice for larger lesions [30]. Unfortunately, larger lesions are of particular interest for cell-based therapies. Autologous chondrocyte transplantation and osteochondral transfer are the treatments most often used for larger defects; therefore, studies designed to evaluate matrix-assisted chondrocyte transplantation compared with autologous chondrocyte transplantation and osteochondral transfer, rather than microfracture-which has already demonstrated inferiority in cases of larger defects [30]—should be encouraged.

In regard to which matrices are best to use for matrixassisted chondrocyte transplantation, the data are of poorer quality and even matrices with the most available data are having trouble gaining regulatory approval. This underscores the poor-quality data to support the individual products currently available. It is encouraging to see randomized controlled trials performed that are starting to give us answers; for example, the recent randomized controlled trial of NeoCart ${ }^{\mathrm{TM}}$ that showed improved pain and function scores compared with microfracture [6]. The lack of uniform outcomes measures also makes it extremely difficult to compare different products. The lack of high-quality studies in the field of cartilage repair matrices and the increased regulations placed on cell-based therapies highlight the need for large, multicenter, randomized controlled studies to further substantiate the benefits of different cartilage repair matrices already demonstrated in small case series given that the regulatory hurdles placed by the US Food and Drug Administration (FDA) have hindered the introduction of matrix-assisted chondrocyte transplantation for cartilage repair [27]. Additionally, the European Medical Association (EMA) has recently increased regulation of these devices in Europe. Hyalograft ${ }^{\mathrm{R}} \mathrm{C}$ is one of the most often used and studied matrices for matrix-assisted chondrocyte transplantation, but the EMA removed it from the European market in early 2013. The EMA expressed concerns of manufacturing practices and quality of comparative studies submitted for approval, so the company withdrew their application for approval based on the EMA's preliminary report. However, given the regulatory hurdles for matrix-based technologies and the financial implications of this, the industry has developed alternatives. The manufacturer of DeNovo-Natural Tissue combined allograft particulated juvenile cartilage with 
fibrin adhesive to create a product that got regulatory approval as a minimally processed allograft in the United States $[9,27]$. As a cell source, DeNovo-Natural Tissue offers significant theoretical benefits with increased replicative and matrix synthetic ability compared with adult chondrocytes [1, 22, 38]. Similarly, other companies are producing minimally processed allograft tissue matrices. The first case series on DeNovo-Natural Tissue recently was published and shows promising results compared with other available techniques $[9,41]$. Time will reveal whether allograft tissue matrices can fill the need for cartilage repair in the United States or whether they will become substandard treatments that will attain FDA approval as minimally processed allografts and not investigational devices, therefore being significantly less expensive and easier to get to market without the need for large randomized studies proving efficacy [27].

Future treatments will likely include an optimized combination of cell sources such as juvenile chondrocytes or the cadre of stem cell sources currently being investigated in preclinical studies with matrices interlacing extracellular matrix molecules and growth factors to support cartilage regeneration [7]. Until such treatments are available, we need to further determine the use of available cartilage repair techniques to pave the way for future innovations. Current evidence suggests that matrix-assisted chondrocyte transplantation has improved patient-reported outcomes compared with microfracture. There is no definitive evidence for preference of one matrix product compared with another given the lack of comparative studies in the literature. Matrix-assisted chrondrocyte implantation and Hyalograft ${ }^{\mathbb{R}} \mathrm{C}$ have the most published studies supporting their use; however, Hyalograft ${ }^{\mathbb{R}}$ $\mathrm{C}$ has recently been removed from the market. Further studies are needed to confirm the benefits of these products and the justification of their cost before widespread use. The FDA approval process may provide an avenue to answer some of the remaining questions.

\section{References}

1. Adkisson HD, Martin JA, Amendola RL, Milliman C, Mauch KA, Katwal AB, Seyedin M, Amendola A, Streeter PR, Buckwalter JA. The potential of human allogeneic juvenile chondrocytes for restoration of articular cartilage. Am J Sports Med. 2010;38:1324-1333.

2. Anders S, Volz M, Frick H, Gellissen J. A randomized, controlled trial comparing Autologous Matrix-Induced Chondrogenesis $\left(\mathrm{AMIC}^{\mathrm{R}}\right.$ ) to microfracture: analysis of 1- and 2-year follow-up data of 2 centers. Open Orthop J. 2013;7:133-143.

3. Bartlett W, Skinner JA, Gooding CR, Carrington RWJ, Flanagan AM, Briggs TWR, Bentley G. Autologous chondrocyte implantation versus matrix-induced autologous chondrocyte implantation for osteochondral defects of the knee: a prospective, randomised study. J Bone Joint Surg Br. 2005;87:640-645.
4. Basad E, Ishaque B, Bachmann G, Stürz H, Steinmeyer J. Matrixinduced autologous chondrocyte implantation versus microfracture in the treatment of cartilage defects of the knee: a 2-year randomised study. Knee Surg Sports Traumatol Arthrosc. 2010;18:519-527.

5. Brittberg M. Cell carriers as the next generation of cell therapy for cartilage repair: a review of the matrix-induced autologous chondrocyte implantation procedure. Am J Sports Med. 2010;38:1259-1271.

6. Crawford DC, DeBerardino TM, Williams RJ. NeoCart, an autologous cartilage tissue implant, compared with microfracture for treatment of distal femoral cartilage lesions. J Bone Joint Surg Am. 2012;94:979-989.

7. Cucchiarini M, Madry H, Guilak F, Saris DB, Stoddart MJ, Koon Wong M, Roughley P. A vision on the future of articular cartilage repair. Eur Cell Mater. 2014;27:12-16.

8. Easterbrook PJ, Berlin JA, Gopalan R, Matthews DR. Publication bias in clinical research. Lancet. 1991;337:867-872.

9. Farr J, Tabet SK, Margerrison E, Cole BJ. Clinical, radiographic, and histological outcomes after cartilage repair with particulated juvenile articular cartilage: a 2-year prospective study. Am $J$ Sports Med. 2014;42:1417-1425.

10. Ferruzzi A. Autologous chondrocyte implantation in the knee joint: open compared with arthroscopic technique comparison at a minimum follow-up of five years. J Bone Joint Surg Am. 2008;90:90.

11. Gille J, Behrens P, Volpi P, Girolamo L, Reiss E, Zoch W, Anders S. Outcome of Autologous Matrix Induced Chondrogenesis (AMIC) in cartilage knee surgery: data of the AMIC Registry. Arch Orthop Trauma Surg. 2012;133:87-93.

12. Gomoll AH. Microfracture and augments. J Knee Surg. 2012;25:9-15.

13. Gomoll AH, Farr J, Gillogly SD, Kercher JS, Minas T. Surgical management of articular cartilage defects of the knee. Instr Course Lect. 2011;60:461-483.

14. Gooding CR, Bartlett W, Bentley G, Skinner JA, Carrington R, Flanagan A. A prospective, randomised study comparing two techniques of autologous chondrocyte implantation for osteochondral defects in the knee: periosteum covered versus type I/III collagen covered. Knee. 2006;13:203-210.

15. Hjelle K, Solheim E, Strand T, Muri R, Brittberg M. Articular cartilage defects in 1,000 knee arthroscopies. Arthroscopy. 2002;18:730-734.

16. Hoemann C, Kandel R, Roberts S, Saris DBF, Creemers L, Mainil-Varlet P, Methot S, Hollander AP, Buschmann MD. International Cartilage Repair Society (ICRS) recommended guidelines for histological endpoints for cartilage repair studies in animal models and clinical trials. Cartilage. 2011;2:153-172.

17. Knutsen G, Drogset JO, Engebretsen L, Grøntvedt T, Isaksen V, Ludvigsen TC, Roberts S, Solheim E, Strand T, Johansen O. A randomized trial comparing autologous chondrocyte implantation with microfracture findings at five years. J Bone Joint Surg Am. 2007;89:2105.

18. Knutsen G, Engebretsen L, Ludvigsen TC, Drogset JO, Grøntvedt T, Solheim E, Strand T, Roberts S, Isaksen V, Johansen O. Autologous chondrocyte implantation compared with microfracture in the knee. A randomized trial. J Bone Joint Surg Am. 2004;86:455-464.

19. Kon E, Filardo G, Berruto M, Benazzo F, Zanon G, Villa Della S, Marcacci M. Articular cartilage treatment in high-level male soccer players: a prospective comparative study of arthroscopic second-generation autologous chondrocyte implantation versus microfracture. Am J Sports Med. 2011;39:2549-2557.

20. Kon E, Filardo G, Di Matteo B, Perdisa F, Marcacci M. Matrix assisted autologous chondrocyte transplantation for cartilage treatment: a systematic review. Bone Joint Res. 2013;2:18-25. 
21. Kon E, Gobbi A, Filardo G, Delcogliano M, Zaffagnini S, Marcacci M. Arthroscopic second-generation autologous chondrocyte implantation compared with microfracture for chondral lesions of the knee: prospective nonrandomized study at 5 years. Am J Sports Med. 2008;37:33-41.

22. Liu H, Zhao Z, Clarke RB, Gao J, Garrett IR, Margerrison EEC. Enhanced tissue regeneration potential of juvenile articular cartilage. Am J Sports Med. 2013;41:2658-2667.

23. Manfredini M, Zerbinati F, Gildone A, Faccini R. Autologous chondrocyte implantation: a comparison between an open periosteal-covered and an arthroscopic matrix-guided technique. Acta Orthop Belg. 2007;73:207-218.

24. Marcacci M, Berruto M, Brocchetta D, Delcogliano A, Ghinelli D, Gobbi A, Kon E, Pederzini L, Rosa D, Sacchetti GL, Stefani G, Zanasi S. Articular cartilage engineering with Hyalograft C. Clin Orthop Relat Res. 2005;435:96-105.

25. McCarthy HS, Roberts S. A histological comparison of the repair tissue formed when using either Chondrogide or periosteum during autologous chondrocyte implantation. Osteoarthritis Cartilage. 2013;21:2048-2057.

26. McCormick F, Harris JD, Abrams GD, Frank R, Gupta A, Hussey $\mathrm{K}$, Wilson $\mathrm{H}$, Bach B, Cole B. Trends in the surgical treatment of articular cartilage lesions in the United States: an analysis of a large private-payer database over a period of 8 years. Arthroscopy. 2014;30:222-226.

27. McGowan KB, Stiegman G. Regulatory challenges for cartilage repair technologies. Cartilage. 2012;4:4-11.

28. Minas T. A primer in cartilage repair. J Bone Joint Surg Br. 2012;94:141-146.

29. Mithoefer K, Saris DBF, Farr J, Kon E, Zaslav K, Cole BJ, Ranstam J, Yao J, Shive M, Levine D, Dalemans W, Brittberg M. Guidelines for the design and conduct of clinical studies in knee articular cartilage repair: International Cartilage Repair Society recommendations based on current scientific evidence and standards of clinical care. Cartilage. 2011;2:100-121.

30. Moran CJ, Pascual-Garrido C, Chubinskaya S, Potter HG, Warren $\mathrm{RF}$, Cole BJ, Rodeo SA. Restoration of articular cartilage. J Bone Joint Surg Am. 2014;96:336-344.

31. Safran MR, Seiber K. The evidence for surgical repair of articular cartilage in the knee. J Am Acad Orthop Surg. 2010;18: 259-266.

32. Saris D, Price A, Widuchowski W, Bertrand-Marchand M, Caron J, Drogset JO, Emans P, Podskubka A, Tsuchida A, Kili S, Levine D, Brittberg M, on behalf of the SUMMIT study group. Matrix-applied characterized autologous cultured chondrocytes versus microfracture: two-year follow-up of a prospective randomized trial. Am J Sports Med. 2014;42:1384-1394.

33. Saris DBF, Vanlauwe J, Victor J, Almqvist KF, Verdonk R, Bellemans J, Luyten FP, for the TIG/ACT/01/2000\&EXT Study Group. Treatment of symptomatic cartilage defects of the knee: characterized chondrocyte implantation results in better clinical outcome at 36 months in a randomized trial compared to microfracture. Am J Sports Med. 2009;37:10S-19S.
34. Saris DBF, Vanlauwe J, Victor J, Haspl M, Bohnsack M, Fortems Y, Vandekerckhove B, Almqvist KF, Claes T, Handelberg F, Lagae K, van der Bauwhede J, Vandenneucker H, Yang KGA, Jelic M, Verdonk R, Veulemans N, Bellemans J, Luyten FP. Characterized chondrocyte implantation results in better structural repair when treating symptomatic cartilage defects of the knee in a randomized controlled trial versus microfracture. Am J Sports Med. 2008;36:235-246.

35. Schulze-Tanzil G. Activation and dedifferentiation of chondrocytes: implications in cartilage injury and repair. Ann Anat. 2009; 191:325-338.

36. Schüttler KF, Schenker H, Theisen C, Schofer MD, Getgood A, Roessler PP, Struewer J, Rominger MB, Efe T. Use of cell-free collagen type I matrix implants for the treatment of small cartilage defects in the knee: clinical and magnetic resonance imaging evaluation. Knee Surg Sports Traumatol Arthrosc. 2013;22:1270-1276.

37. Shetty AA, Kim SJ, Bilagi P, Stelzeneder D. Autologous collagen-induced chondrogenesis: single-stage arthroscopic cartilage repair technique. Orthopedics. 2013;36:e648-e652.

38. Smeriglio P, Lai JH, Dhulipala L, Behn AW, Goodman SB, Smith RL, Maloney W, Yang F, Bhutani N. Comparative potential of juvenile and adult human articular chondrocytes for cartilage tissue formation in 3D biomimetic hydrogels. Tissue Eng Part A. 2014 Oct 1 [Epub ahead of print].

39. Steadman JR, Rodkey WG, Rodrigo JJ. Microfracture: surgical technique and rehabilitation to treat chondral defects. Clin Orthop Relat Res. 2001;391(Suppl):S362-369.

40. Stelzeneder D, Shetty AA, Kim SJ, Trattnig S, Domayer SE, Shetty V, Bilagi P. Repair tissue quality after arthroscopic autologous collagen-induced chondrogenesis (ACIC) assessed via T2* mapping. Skeletal Radiol. 2013;42:1657-1664.

41. Thomkins M, Hamann JC, Diduch DR, Bonner KF, Hart JM, Gwathmey FW, Milewski MD, Gaskin CM. Preliminary results of a novel single-stage cartilage restoration technique: particulated juvenile articular cartilage allograft for chondral defects of the patella. Arthroscopy. 2013;29:1661-1670.

42. Van Assche D, Staes F, Van Caspel D, Vanlauwe J, Bellemans J, Saris DB, Luyten FP. Autologous chondrocyte implantation versus microfracture for knee cartilage injury: a prospective randomized trial, with 2-year follow-up. Knee Surg Sports Traumatol Arthrosc. 2009;18:486-495.

43. Vanlauwe J, Saris DBF, Victor J, Almqvist KF, Bellemans J, Luyten FP, TIG/ACT/01/2000\&EXT Study Group, Bohnsack M, Claes T, Fortems Y, Handelberg F, Haspl M, Jelic M, Lagae K, Vandekerckhove B, Vandenneucker H, van der Bauwhede J, Verdonk R. Five-year outcome of characterized chondrocyte implantation versus microfracture for symptomatic cartilage defects of the knee: early treatment matters. Am J Sports Med. 2011;39:2566-2574.

44. Zeifang F, Oberle D, Nierhoff C, Richter W, Moradi B, Schmitt H. Autologous chondrocyte implantation using the original periosteum-cover technique versus matrix-associated autologous chondrocyte implantation: a randomized clinical trial. Am J Sports Med. 2010;38:924-933. 